INVESTIGACIONES 



\title{
REDES SOCIALES Y JUVENTUD
}

\section{SOCIAL NETWORKING AND YOUTH}

\author{
María Francisca Quintanilla Paulet*
}

\section{RESUMEN}

En este artículo, la autora nos presenta el fruto de su investigación sobre la relación entre el mundo virtual y la juventud. Ese desafío que supone el nuevo entorno es presentado aquí con una revisión desde las dimensiones psicológicas, sociales y educativas. Las posibles consecuencias de su mal uso, así como las oportunidades al que esta nueva situación nos conduce también son mostradas. Finalmente, se sugieren posibles alertas a tomar en cuenta tanto por los padres como por los educadores.

\section{PALABRAS CLAVES:}

Redes sociales, Internet, Web 2.0, nativos digitales, identidad juvenil.

\begin{abstract}
In this article, the author presents the fruits of his research on the relationship between the virtual world and youth. The challenge of the new environment is presented here with a review from the psychological, social and educational dimensions. The possible consequences of the misuse, as well as the opportunities that this new situation leads, are also shown. Finally, recomendations to take account both by parents and by educators are suggested.
\end{abstract}

\section{KEY WORDS:}

Social networking, Internet, Web 2.0, digital natives, youth identity.

* Religiosa del Sagrado Corazón y Docente del Instituto Pedagógico Nacional Monterrico: quintanillamf@ hotmail.com 
Vivimos esta época en un nuevo escenario. El mundo actual experimenta una intensa transformación: la "mundialización" que sitúa al ser humano en una situación profundamente modificada, cambia la vida y la sociedad. La globalización del mercado y sus consecuencias en la sociedad han puesto en el centro de la actividad económica y social al conocimiento, a la globalización de la economía y a las TIC's, es decir, a las Tecnologías de la Información y la Comunicación. No se trata sólo de un cambio cultural; en este nuevo escenario, internet y las TIC's han cambiado básicamente el mundo de la relación. Internet es una infraestructura tecnológica y un medio de organización que permite y promueve nuevas formas de relación social.

\section{La era de la realidad virtual}

El ser humano vive una nueva era: la era de la realidad virtual, del mundo virtual. La palabra "virtual" significa en el lenguaje informático algo creado por la computadora para producir lenguaje escrito, imágenes y sonidos. Los albores de esta realidad se remontan al momento en el que en el cine se empieza a producir, a la vez, imagen y sonido.

En 1969, por primera vez se interconectan las computadoras. En 1970 se sigue buscando nuevos caminos para la computación. En la Web pc-actual.com se hace alusión a Tim Paterson quien en 1978 empieza a trabajar varios diseños en DOS. El 15 de marzo de 1985 se registra el primer Dominio de la historia de internet, lo que inicia una revolución tecnológica que ha cambiado estructuras sociales y económicas en todo el mundo. Symbolics. com fue la pionera de la fiebre del "punto. com". Pero hablando de internet, según la Web tufuncion.com, se consolida a fines de 1990. Internet, ha supuesto - dice - "una revolución sin precedentes en el mundo de la informática y de las comunicaciones". Durante estos años internet ha modificado y sigue modificando, en gran medida, la vida de las personas y, especialmente, la de los jóvenes. Actualmente internet juega un papel muy importante en el diario quehacer; incluso el 17 de mayo es día internacional de internet, fecha aprobada por la ONU el 2006. En el siglo XXI tenemos la Web 2.0, con la que aparecen las redes sociales, y la web 3.0 que habla hoy de técnicas de inteligencia artificial.

Se ha pasado de ser "visitante" de una página a ser "participante", a través de las llamadas redes sociales como Facebook, YouTube, Twitter, LinkedIn, Badoo, entre otras, que favorecen la interrelación permitiendo contenidos multimedia, como colgar fotos, videos, audio y otros. Gracias a las nuevas tecnologías, los jóvenes, "nativos digitales", entienden las cosas de manera diferente. El reto de los adultos es seguirles el paso y aprender juntos. Actualmente se habla de inmigrantes y nativos indicando que los de mente gramatical son inmigrantes porque emigran del libro a las nuevas tecnologías $y$, en cambio, los nativos digitales son los que han nacido con la computadora.

El concepto de nativos digitales aparece a inicios del Siglo XXI con Mark Prensky, estadounidense especializado en temas educativos; él sostiene que los nativos digitales piensan y procesan la información de manera diferente. En cambio, el inmigrante digital según Prensky, es quien aprende a adaptarse a este nuevo ambiente pero que, de alguna forma, siempre tiene un pie puesto en el pasado. Todo lo anterior nos puede ayudar a comprender el modo de ser, pensar y actuar de nuestros jóvenes actuales. En cuanto a las relaciones sociales que se crean a través de internet es muy distinto el modo de relacionarse, 
de buscar, de obtener información y, también, de compartirla. Actualmente se presentan nuevas situaciones: si un niño no tuviera contacto con seres humanos sería retrasado, así también, si algún niño sólo tuviese contacto con internet, sería retrasado y esto es comprensible porque no podría desarrollar habilidades que se adquieren en el contacto directo con las personas. Hay nuevas patologías por el excesivo uso de internet: una especie de autismo informático; por ejemplo los utakus japoneses, que nunca salen de casa y sólo se relacionan por la red. Es evidente que estos nuevos ermitaños informáticos no despliegan todas sus potencialidades.

Hablando de internet, algo interesante fue el lanzamiento de la página del Papa Benedicto XVI en Facebook el domingo 24 de mayo del 2009 y la del Papa Francisco el 2013 que han atraído el interés de los medios y a la que ingresan numerosos jóvenes internautas visitantes. El lanzamiento de la página el 2009 coincidió con la 43a Jornada Mundial de las Comunicaciones Sociales de la Iglesia Católica y muestra cómo los Papas, no sólo se interesan por las nuevas tecnologías de la comunicación, sino que las reconocen como un medio importante en este escenario tan decisivo de lo humano.

En cuanto a las TIC's, se van desarrollando diferentes propuestas para el joven actual, usuario cotidiano de la tecnología, como "nativo digital", que utiliza la red para crear, recrear, interactuar y hacer comunidad. Es hábil en acceder, almacenar, transformar y generar información a nivel de texto, imagen y sonido.

Es a fines de los años 80 que se habla ya de esta realidad y, como dice la enciclopedia temática Espasa "Ha tenido una creciente difusión en el gran público" y se enuncia "la identificación de la realidad virtual como conjunto de determinados dispositivos electrónicos" (1998, p.667).

\subsection{Internet y sus entornos.}

Internet no es simplemente una red; es una red de redes que están interconectadas. No se puede decir que exista una organización que sea "dueña" de internet pero sí hay lo que se llama "ruteadores" que examinan y envían. Internet se considera un fenómeno social, de grandes alcances que presta importantes servicios porque permite la comunicación directa y al momento, de manera fácil y clara, a lo largo y ancho del mundo. Internet se ha introducido con increíble rapidez en la vida diaria. Esta velocidad ha impedido que nos distanciemos un poco para observar, analizar la influencia positiva y/o negativa que pueda tener. Internet es un entorno virtual que incluso los mismos usuarios, en cierto sentido, pueden cambiar.

El acceso a internet progresa con rapidez entre los jóvenes de Latinoamérica y del Perú. Observando a cualquier grupo juvenil se percibe que son capaces de ver TV y al mismo tiempo estar en la red, enviar mensajes de texto y usar el celular con velocidad, crear blogs, bajar videos de YouTube, mientras hacen sus trabajos. Es una interacción de cada día, que supone habilidad para crear o recrear el pensamiento y procesar información, manipulando digitalmente. En el Perú se dan cambios significativos en cuanto a infraestructura y al uso de la red: hay cabinas en innumerables lugares; numerosas familias están en red; se usa con frecuencia el smartphone y las tablets.

El impacto de internet es muy significativo; es para los jóvenes un instrumento de información, de comunicación y de diversión al momento. 
Ellos han nacido en la era digital. Están inmersos en un conjunto de prácticas marcadas por lo tecnológico que los predispone, de manera diferente, para acceder a la información y al conocimiento. La Web (World Wide Web) combina diversos servicios; a través de ella se logra todo tipo de información, mediante buscadores; se ubica documentos o fotos, se busca libros en bibliotecas u obras de arte en los museos; se consigue teléfonos y direcciones. Los servicios que ofrece son innumerables, tanto a nivel informal como formal. Se pueden leer diarios y revistas, consultar artículos, participar en juegos. El intercambio de información y el poder utilizar fuentes para la investigación es muy valioso. Existen, por otro lado, entornos educativos y profesionales, especialmente usados por quienes desean investigar y compartir. En la red hay también la posibilidad de entornos muy creativos: gráficos con movimiento, música y sonido que incluyen personajes hasta con cierta personalidad.

Cabero y Duarte, al hablar sobre las redes de comunicación, enumeran algunas características: "Multidireccionalidad, interactividad ilimitada, multiformato, flexibilidad temporal: flexibilidad en la recepción. Entornos abiertos y cerrados. Y esto hace muy atractivo el trabajo en la red" (2000, p.167).La Web 2.0 tiene como característica hacer protagonistas a los propios usuarios, quienes son participantes y la alimentan siendo, incluso, autores de un alto porcentaje de los contenidos de la red. Ofrece servicios y aplicaciones que facilitan la publicación de contenidos de tipo digital y la organización de los mismos. Esto sucede con Facebook o Twitter. El fenómeno de Twitter, aclamado o criticado, pero con muchos adeptos y que crece cada día; puede ser considerado como una puerta de escape para los jóvenes quienes pueden comunicar a sus amigos lo que hacen en cada momento, por eso es llamado microblogging; puede definirse como red social que es, al mismo tiempo, correo electrónico. Nuestros/as jóvenes participan en estas comunidades virtuales permanentemente.

La Web 3.0, innovación tecnológica, tiene como objetivo lograr la inteligencia artificial con las siguientes características: Sociabilidad, dando la posibilidad de tener mayor número de identidades en la red. Inteligencia, haciendo posible preguntar a la web en el propio idioma y sin necesidad de usar clave, sobre algún tema. Rapidez, facilitando la conexión entre usuarios. Apertura, pudiendo utilizar software e información libre, lo que supone un uso más democrático. Facilidad en el uso, por ser una web más homogénea en las funciones y fácil de reconocer, pudiéndose configurar según el gusto del usuario. Distribución mayor, dado que la web tiene enorme espacio que permite realizar tareas como una gran computadora universal. Tridimensional, en el espacio que permite dispositivos para moverse por la red.

\section{Juventud}

Los jóvenes de hoy han nacido después del 90; para ellos el mundo de la informática es tan normal como para los adultos el cine o la televisión; tal vez por eso, muchas veces los jóvenes son imaginativos pero sin ilusión; con fuertes experiencias pero fragmentados; con estética pero sin empuje. Los padres y educadores necesitan comprenderlos en su manera de ser pero, al mismo tiempo, buscar formas creativas para ayudarlos en el manejo de la cultura virtual, sabiendo que son así pero que pueden llegar a ser diferentes: mucho mejores.

La etapa juvenil es una edad rica en la que se consolida la personalidad, crece la vida consciente y reflexiva. Es la 
etapa en que se pasa del pensamiento concreto al pensamiento abstracto. Al mismo tiempo crecen las oportunidades de ubicación en la sociedad. Es un período rico, pero muchas veces difícil porque está condicionado por el pasado y puede condicionar el futuro. Es un tiempo de llamada y de respuesta a muchas posibilidades para llegar a alcanzar la madurez plena.

\subsection{Internet y conducta juvenil.}

Conviene partir de una realidad: el mundo virtual puede ser aceptado o rechazado por toda persona. Nadie puede imponerlo. El ser humano lo ha creado, lo ha producido y lo va manteniendo, pero puede también ignorarlo, aunque esto sea muy difícil hoy. Las TIC's, Tecnologías de la Información y la Comunicación, cambian el mundo de la juventud que hoy es distinto del de hace cinco años. Es necesario preguntarse si se trata de cambio en el mundo de las relaciones; si hay modificaciones en el mundo del aprendizaje. Por un lado, se advierte que al joven le resulta más agradable entrar al mundo de la visualización digital que al material impreso: la imagen, el movimiento y el sonido son mejor acogidos que los textos escritos y esto debe ser aprovechado. Incluso, la velocidad en la información - de ida y de vuelta - la considera importante, lo mismo que hacer varias cosas al mismo tiempo. Por otro lado, le subyuga poder intercambiar con personas de otros países y culturas.

Todo lo anterior es positivo pero es necesario reconocer también sus aspectos negativos como es que muchas veces lleva a preferir el ingreso a la red que estudiar; a actuar, por rapidez, con superficialidad; a buscar lo fácil en contra de lo mejor. La juventud está inmersa en este mundo digital que es irreversible. La psicología nos enseña que el ambiente y el entorno condicionan. Esta ley se puede aplicar también a los cambios que pueden producirse en la conducta, por influencia del "entorno virtual". Los estudiosos de la conducta humana aseguran que los contextos diferentes influyen en la actitud de las personas que, poco a poco, van modificando su comportamiento. Esto mismo puede ocurrir en el entorno de internet. Es verdad que este fenómeno no está del todo estudiado, pero se puede hablar ya de paralelismos; si se habla del tema de la afectividad, por ejemplo, la atracción interpersonal se da a través de la red, como en una relación interpersonal fuera de ella, pero con la diferencia de que al utilizar la red se vuelve más atractiva la comunicación. Utilizando otro paralelismo, la agresividad puede expresarse más en la red, por el hecho del anonimato. Respecto a conductas desinhibidas: la persona que fuera de la red se cuida, cuando está en internet puede actuar con mayor libertad porque no muestra el rostro. En los diversos entornos de la red se puede interactuar de manera anónima o utilizando apodos para esconder la verdadera identidad; esta situación puede llevar a la relajación o desinhibición, que puede influir en la manera de actuar. Puede darse el caso, incluso, en que la persona - al pasar de un entorno a otro - cambia de actitud y su comportamiento no es acorde con su modo real de ser. El hecho de no haber un líder que modere al grupo en un entorno virtual, puede permitir excesos de lenguaje o de "acción virtual". Es cierto, también, que a través de la red, pueden darse cambios positivos de conducta, como el "contagio" para servicios de solidaridad, sea sólo a nivel teórico y de interés como, también, de manera práctica para organización de servicios y ayudas concretas a menor o mayor escala. 


\subsection{Internet y personalidad.}

En la interacción virtual, se pueden dar situaciones que permiten el desarrollo del Yo, diferentes de las que se producen en la vida real, tanto positivas como negativas. Mayans i Planells comenta que "los detractores dicen que así se fomenta la mentira, el fantaseo e incluso conflictos de múltiple personalidad, así como la huida del mundo y de sus problemas reales. Los entusiastas, por su parte, nos llenan los oídos de la facultad imaginativa creadora y positiva que estas experiencias suponen, llegando a decir que, de este modo, cualquiera puede llegar a ser lo que desee" (2002, pp.191-192). Se habla, también, del "travestismo electrónico" como de un fenómeno social bastante común. Puede ser esto considerado como una aberración, una mentira o un ataque a la intimidad de los usuarios. $O$, por otro lado, puede considerarse como creatividad y experiencia que permite el conocimiento de otro género.

Este fenómeno es en sí mismo una forma de mentira que puede dañar la formación de la personalidad. Puede darse el caso de que haya sinceridad en la auto presentación, de manera que el yo real y el yo virtual coincidan; y puede haber una conversación normal en la que la persona hable y actúe con sinceridad y libertad de expresión. Puede ocurrir, también, que haya quienes inventan su personaje y actúan conforme a su creatividad, incluso sin identificarse con él pero considerándolo como un instrumento suyo en el mejor de los casos, o con intenciones torcidas para sacar provecho del anonimato. Conviene preguntarse si este tipo de actitudes influye en la formación o deformación de la personalidad. En la vida normal, fuera de la red, las expresiones faciales dan a conocer el modo de ser: Un gesto, una postura, una mirada pueden expresar el interior $\mathrm{y}$, ciertamente, la palabra puede ser menos importante que el gesto. En la red es diferente, dado que la palabra escrita está en primer plano y, en general, en la red la persona es más concreta que en la vida real; y es por eso mismo que, quizá, en el afán de ganar tiempo, se evite cualquier detalle o palabra amable y se muestre una personalidad más fría que la verdadera. Fuera de la red se usa inflexiones de la voz que pueden suavizar por ejemplo un desacuerdo, lo que no ocurre en la red.

Se ve posiblemente como normal entrar en el ciberespacio sin preocuparse mucho de la personalidad, de la impresión que se da y de la influencia que puede tener el modo de ser. La persona es consciente de que, si en la red parece brusca y tal vez dura, quienes la conocen matizarán esa impresión. Pero si es con personas desconocidas o si se trata de un primer contacto a través de la red, se tiene que tener cuidado con la imagen que se proyecta a través de la misma. Se puede dar una impresión fría o calurosa, agradable o desagradable, sobre todo si-por cuestión de tiempo - se va directamente al tema y se evitan las frases cortas y amables que se usan en el contacto real. A veces, una sonrisa o un gesto pueden cambiar el ambiente en una conversación y dar un giro positivo en un momento difícil; esto no es fácil en la red a pesar de que sería lo conveniente. Felizmente hay usuarios de internet que descubren esta necesidad, como dice Wallace, "de manera intuitiva, los usuarios de la red empezaron a darse cuenta de la necesidad de encontrar mejores maneras de trasmitir sus sentimientos y emociones" (2001, p.369). Una manera de dar calor al ambiente de internet fue la creación de los "emoticonos" para representar emociones, como también el uso de frases cortas y agradables.

Hablando de internet y personalidad del joven, es preciso insistir en que 
internet ha entrado, con mucha velocidad, en la vida de la juventud. Es eficaz instrumento para entrar en contacto con compañeros y amigos; para compartir preocupaciones y alegrías con los pares; para el estudio y el trabajo. La juventud usa, con mucha frecuencia las redes sociales y, como dice Faerman, "los usuarios pueden participar en una o más redes sociales. en relación con su situación académica, su lugar de trabajo o región geográfica" (2009, p.17). La entrada de internet en la vida ha sido y sigue siendo tan rápida que es difícil analizar sus efectos sobre la personalidad juvenil. Por otro lado, toda persona puede actuar positiva o negativamente en ese entorno, influyendo en percepciones y conductas. Es interesante lo que dice Wallace "Internet es un lugar en el que, en ocasiones, actuamos e interactuamos de una manera bastante extraña. Unas veces sus efectos parecen ser muy positivos, pero otras hacemos cosas que nunca haríamos en otros entornos y de las que después nos podemos arrepentir (2001, p. 16). Los tecnólogos, en su afán de hacer "más humano" el mundo de internet han creado los "avatares" que pueden - gracias a un simple clic - bailar de alegría o aparecer furiosos con los puños en alto; estos gestos pueden estar acompañados de sonido. La juventud gusta mucho de expresar, así, sus sentimientos.

Algo muy importante para los usuarios de la red es saber la edad y el sexo. Preguntar directamente estos datos es la forma más rápida, pero a veces no se logra el resultado propuesto. Es importante la claridad en este punto para el desarrollo de la conversación. Averiguar el sexo no es tan difícil: por la firma o el apodo se puede descubrir. Una manera de lograrlo es "empleando una "sonsaca estratégica" que recibe el nombre de Morfing, que es una abreviatura de Male or Female (¿hombre o mujer?)" como dice Wallace (2001, p.41) Es necesaria la claridad en este punto para el desarrollo del encuentro. Otros datos importantes, también, son la nacionalidad y la raza. Puede que los usuarios no quieran dar la impresión de tener prejuicios raciales o, tal vez, realmente no los tengan. Lo que sí es normal es que el joven quiera impresionar en la red - como lo intenta en la vida real y en este campo es muy creativo. El uso de apodos es muy frecuente y así establecen, muchas veces, su personalidad en la red.

\subsection{Identidad juvenil en la red.}

Nuestros jóvenes han nacido, todos, en el último decenio del Siglo XX y su búsqueda de identidad está abierta a muchos modelos; por esto es normal que miren al mundo con otra perspectiva, como dice Perinat, su futuro "se construye hoy sobre un imaginario cultural colectivo de dimensiones inusitadas: globalización de la economía, red de comunicaciones mundial al alcance de todos, representación de un mundo de progreso imparable, incertidumbres ecológicas y económicas, y otras, que integran el panorama del comienzo del siglo" (2003, p.60). Como vemos, entre las dimensiones está la red de comunicaciones que pone a disposición de la juventud una amplia información, numerosas fuentes de conocimiento que sirven para sus estudios y son, también, instrumentos para la relación interpersonal.

Actualmente se habla de "identidades artificiales" porque quienes participan en la red pueden falsificar su identidad, tal vez, como un juego o diversión, distorsionando la verdad. Puede darse el caso, así, de identidades múltiples y/o paralelas. ¿Será positivo que una persona - y concretamente un joven - pueda actuar con varios "yo"? ¿De qué manera esto puede influir en su personalidad? ¿Pueden darse ciertas transformaciones por el hecho de estar varias horas en la red asumiendo diversas identidades? ¿De qué manera este interactuar en red influye en su personalidad? Según Quiroz, 
(2004) las identidades artificiales "estarían disolviendo las fronteras de la identidad", y esto porque al cambiar su identidad estarían mostrando que les gustaría ser diferentes o que quisieran tener otra personalidad. A través de internet se pueden tener identidades paralelas, entonces es válida la pregunta: ¿esta posibilidad puede cambiar su sensibilidad social? ¿Puede decirse que poseen varios yo mientras interactúan en la red? Entonces, los jóvenes que pasan varias horas en internet usando diversas identidades, ¿̇pueden mantener su identidad real? La red es un espacio virtual que permite tener identidades diferentes con diversos tipos de relación, es decir, que facilita diversas formas de interacción. Es verdad que la persona puede jugar varios y diferentes papeles en la vida real: ser madre o padre y profesional, y seguir siendo ella misma y ¿qué pasa a través de internet? Hoy en la red social la identidad se da a conocer no sólo por la palabra escrita sino por la imagen: fotos que el joven publica arreglando su página personal, llamando la atención y mostrando muchas veces no sólo lo que es sino lo que quisiera ser. Todo esto demanda tiempo y puede llevar a crear una identidad ficticia diferente de la real.

\subsection{La comunicación en la red.}

Mirando este tema desde la experiencia, internet ha ayudado y sigue ayudando a la comunicación; esta ha crecido enormemente desde la aparición de la red. Las relaciones en internet pueden ser superficiales o profundas, inestables o muy prolongadas, pero, de todos modos, son ocasión para el encuentro. Cuando, a través de internet, dos personas encuentran afinidad y simpatía suelen pasar a una relación más cercana. Esta es una oportunidad para encontrar conocidos, iniciar o afianzar amistades. A través de internet se da la aproximación, a veces por casualidad o por coincidencia; es proximidad virtual que puede coincidir o no con la lejanía física. La proximidad puede darse por un encuentro en la red y puede llegar hasta una auténtica amistad. Esta amistad puede ir creciendo por el descubrimiento de ideas o actitudes semejantes, como se da en la vida real. El intercambio es más fácil y con mejores resultados cuando se dan muestras de interés mutuo o de valoración. El humor es muy importante en la comunicación para las buenas relaciones virtuales, como dice Wallace "En internet el humor puede ser un factor muy poderoso en la atracción interpersonal, sobre todo porque no está ensombrecido por la apariencia física. El humor se puede expresar con mucha facilidad en la red, simplemente a través del texto." (2001, p.193). El buen humor se expresa por chistes, juegos, frases ingeniosas y en algunos casos - si la persona es de mal gusto - por bromas con burlas o ironías. El buen humor puede favorecer la confianza y apertura, creando ambiente de comodidad propicio a la confiabilidad, camino para la auténtica amistad. Se sabe que el estilo de hablar por teléfono es diferente al lenguaje diario. Esta característica normal, se agudiza en internet porque el entorno influye, lo mismo que las normas sociales. El hecho de tener que usar el teclado para la comunicación influye en el lenguaje escrito: se intenta trasmitir muchas ideas en pocas palabras. Aparentemente es un lenguaje sin consistencia pero que sirve para la comunicación y, más aún, dado que la persona puede leer dos o más veces antes de proceder a contestar.

La nueva generación de internet trae su propio vocabulario: habla de "surfear" "blog", "wiki", etc.; es usuaria de una Web más abierta y participativa. Un dato interesante es que ya existe en España un diccionario creado por la asociación de usuarios de internet. En la red se da 
el error de usar abreviaturas de manera incorrecta, eliminando consonantes e incluso quitando sílabas completas, lo mismo que tildes, mayúsculas y signos de puntuación. Puede darse, también, que se quiera escribir como se habla. Y esto trae como consecuencia deformaciones que, no por ser deliberadas, son menos incorrectas. Puede darse el caso, incluso, de que el escribir de esa manera sea un modo de esconder la identidad, o usar el lenguaje de manera lúdica como dice Mayans i Planells "Las normas de ortografía $y$ gramática son un reto a desafiar $y$ donde el mero hecho y la forma de desafiarlas constituyen una prueba de originalidad, personalidad, de identificación, y en última instancia, ingenio" (2002, p.86).Es interesante, por otro lado, el modo como se comparten las emociones; para ello, el uso de expresiones escritas es complementado o remplazado por los "emoticonos" o smilies. Es término que se "diminutiza" y se pluraliza según la necesidad y que tiene como materia prima, los signos de cualquier computadora, por ejemplo (:) que puede significar alegría, o $:$ que puede significar fastidio. Los emoticones trasmiten rostros alegres o tristes, coléricos o serenos, y son muy usados en la red. Un emoticono puede trasmitir alegría o asombro. Puede, también, ser un signo, un interrogante, una respuesta que puede completar una frase a color, con negrilla o en cursiva. Es interesante la creatividad utilizada para la conversación, considerando las limitaciones de tiempo y distancia. Es necesario preguntarse si todo este cambio de lenguaje influye y cómo influye en los cambios de personalidad. Actualmente la RAE proyecta una lista de abreviaturas para los SMS, mensajes cortos. Sería necesario que se elaborase la tabla de abreviaturas. Se anuncia que se está trabajando en un corrector de Microsoft, con una base léxica de 500 millones de registros, en el intento de adaptar los conocimientos de la RAE a las nuevas tecnologías. Se está trabajando tres parámetros: ortografía, nueva gramática y diccionario en red, con el afán de dar una respuesta a quienes escriben por internet o a través de celulares.

Otro aspecto interesante se da también en la red con alguna forma de buena educación, de comportamiento, lo que en el ciberespacio se suele llamar netiquette, que brota de un compromiso entre los cibernautas. Ciertamente la red es buena oportunidad para romper fronteras sociales, lo que permite considerarlo expresión de la post-modernidad. Es objeto de estudio muy interesante porque internet es, como dice Mayans i Planells, "Una ciudad digital e imprecisa, temblorosa como las letras en un antiguo monitor de fósforo verde, cambiante a cada minuto, donde las banderas flotan $y$ desaparecen, toda historia es efimera y toda narración nace caduca, hecha $y$ deshecha en un minuto" (2002, p.98). Es interesante la velocidad de la transmisión. La comunicación con sonido es algo natural y cotidiano; se da en un lugar común, la red social, es válido y tiene sus propias reglas, con sus pros y sus contras. Hay redes sociales muy populares como Facebook, Twitter, Badoo y YouTube que tienen millones de adeptos. Faerman, haciendo alusión a la enciclopedia virtual Wikipedia dice: "Los usuarios pueden participar en una o más redes sociales, en relación con su situación académica, su lugar de trabajo o región geográfica" (2009, p.17).

\subsection{Internet y axiología.}

Cada vez es más importante el desarrollo de sentimientos y valores que hacen único al ser humano. Pero en el entorno virtual, muchas veces los derechos de autor no se respetan. Otras veces, contiene "basura" tanto cognitiva como moral. Abundan las páginas pornográficas. Es importante conversar y preguntarse sobre el significado de 
"valor". Puede, es verdad, considerarse una cualidad física, intelectual o moral; puede mirarse como una actitud, un interés, un rasgo. Pero es algo más: aquello que supone interés y estima, aquello que significa. Consideramos el valor como las cualidades positivas, el ideal que forma parte de una escala de valores, jerarquía basada en principios morales. Siendo el ideal lo que debería ser más que lo que es; guía que orienta la conducta en una dirección determinada, es básico en la personalidad. Se sabe, por la psicología, que los valores se desarrollan y crecen de una forma semejante a como se desarrollan los hábitos; es así importante el refuerzo positivo, la estimulación y la retroalimentación. El valor es base o criterio para evaluar un comportamiento que debe guiar la conducta en relación con internet. Los valores giran alrededor de las acciones vividas dentro de las relaciones interpersonales. Aquí, el curioso caso de una niña británica que intentó subastar a su abuela en el portal eBay como publica El Comercio el jueves 1 de octubre del 2009. Zoe Pemberton tomó esta decisión porque su abuela era "rara y molestosa". Hubo ofertas que superaron los \$31,000 pero eBay, con criterio, retiró la oferta dado que iba contra la prohibición de comercio de personas. Fue inconsciencia de una niña, posiblemente, o tal vez travesura, pero conviene preguntarnos cómo podría Zoe llegar a utilizar internet en la etapa de la adolescencia.

Los valores se desarrollan especialmente en la familia, sin olvidar el contacto con los pares y amigos. Es aspecto fundamental en la personalidad. Relacionando valores e internet, es interesante profundizar en lo que puede suponer para el joven la posibilidad de crear su página personal. Es normal y valioso que le interese tener una imagen positiva; pero estar muy pendiente de su propia imagen puede suponer egocentrismo, que lo lleva a sobrestimar el ser observado por otros. Internet puede ir contra los valores porque es ocasión de dedicar un tiempo innecesario a mostrar la personalidad en la red.

Otro aspecto, en cuanto a valores, es que la red da pie a las medias verdades, al engaño, a las exageraciones; el hecho del anonimato lo permite y la distancia física lo provoca. Estas mentiras son tal vez para causar mejor impresión y estar satisfechos con su fingida autoimagen. Es fácil y frecuente representar un rol en la red, muchas veces distinto del real. El cambio de nombre, edad y sexo puede llevar a confusiones; son formas de engaño inaceptables que, además de ir contra la verdad, pueden traer consecuencias muy negativas. Wallace dice: "El cambio de sexo es un aspecto de los juegos de rol que ha hecho que los usuarios de internet se hayan alineado en dos bandos contrarios. (2001) Es inadecuado aparentar ser de otro sexo por diversión, sabiendo que se juega con la fe de otras personas y que, con burdas mentiras, se puede llegar a problemas mayores. El entorno de la red se presta para falsificaciones de esta clase que van contra los valores y afectan a la ética. Esta interpretación va en la línea de los valores y, también, en la línea de la identidad de la personalidad. La persona que cambia su sexo o edad juega con su propia identidad, experimentando diversos roles, posiblemente para tener nuevas experiencias. Es cierto, también, que si se está en internet con una falsa identidad y se da un cansancio de ese "juego" es posible acabar simplemente saliendo de la red. Wallace (2001) dice: "Internet es un laboratorio de identidad que ofrece abundantes accesorios y medios de apoyo, públicos, diversos y jugadores, para nuestros experimentos personales, y aunque muchas personas no se apartan demasiado de su personalidad cotidiana y se limitan a juguetear con unas cuantas características que 
les gustaría mejorar, sobre todo su extraversión, otros se saltan la línea entre el control de la impresión y el engaño. Nos podemos aferrar a la creencia de que nuestros experimentos son divertimentos inofensivos, pero las víctimas de los mismos puede que no estén de acuerdo" (2001, pp.73-74). Ciertamente, el cambiar la identidad puede ser un simple engaño para divertirse, pero puede traer también consecuencias serias como cuando se trata del enamoramiento de una persona que no tiene las características que dice tener. La red permite experimentar, fácilmente, con falsas identidades; y ofrece la dificultad de descubrir y detectar la auténtica identidad de las personas.

En cuanto a la agresividad en la red, es necesario recordar que es una conducta muy compleja; puede haber causas biológicas para la agresividad, tanto en la vida real como en la virtual. Como dice Wallace "gran parte de lo que hacemos es el resultado conjunto de las fuerzas biológicas y medio ambientales" (2001, p. 150). Es cierto, también, que el nivel de la agresividad depende de condiciones y circunstancias; el entorno influye en el nivel de agresividad. Un condicionante importante es la frustración, cuando queremos alcanzar una meta y no lo logramos, porque la tensión alcanza un nivel muy elevado. Es necesario analizar qué elementos en la red predisponen a la violencia.

En la red puede haber motivos para frustración: acceso lento, esperas, caída de la red, ventanas emergentes no deseadas. Son situaciones desagradables que pueden despertar la agresividad; puede ser la última gota para que el vaso se colme. Hay también otros motivos causales de agresividad: recibir una respuesta en la que se advierte la desconfianza o, más aún, recibir un insulto. Esta situación se hace más factible por el hecho de la desinhibición, de la lejanía física y del anonimato. Si alcanza a la persona en la que la susceptibilidad está a flor de piel, no sería raro que la respuesta fuera agresiva, en el deseo de responder con la misma moneda. El hecho de no estar físicamente presentes en el mismo lugar facilita las expresiones de disgusto y agresividad. En la red se da también falta de respeto: en octubre del 2009 para la fiesta de Halloween, la tienda Buyseasons de Washington ofreció un disfraz a través de su Web. El disfraz fue de inmigrante ilegal: traje naranja de presidiario acompañado de una máscara de extraterrestre y una green card (tarjeta de residencia) siendo una ofensa para los millones de indocumentados que tiene el país. Sería falta de respeto hacer broma, burla, mofa de una situación dolorosa para muchos inmigrantes ilegales; este hecho, felizmente, provocó el rechazo de grupos de Derechos Humanos. Situaciones semejantes dan pie para reflexionar sobre la importancia del respeto y de la aceptación de lo diferente.

Otro tema interesante, en relación con la personalidad del joven y los valores en internet, es el de la amistad y el amor. La red es espacio virtual y posibilidad para encontrar amigos y amigas; puede ser espacio para descubrir la auténtica amistad que puede llegar a ser muy profunda y duradera. Como en la vida real, en la relación virtual puede haber grados: contactos superficiales y pasajeros, o llegar a relaciones sólidas y duraderas. Un factor interesante es la atracción interpersonal que puede darse, tanto en la vida real como en la virtual. El atractivo físico es una realidad que influye en la actitud hacia los demás. El aspecto físico es tanto o más importante a veces que la amabilidad, el trato agradable y la inteligencia. A través de la red se puede llegar a conocer a una persona bastante bien. Vivimos un momento en el que hay parejas que se forman a la distancia, y 
otras mantienen una relación sólo por internet, quizá porque eso supone menos riesgo y menos compromiso. Pero esto se da a la par de un nuevo relativismo: sólo es verdad lo que ocurre o está en internet. Esto es grave porque la persona no puede fiarse totalmente de internet, ya que son innumerables los visitantes en la red y pueden subir a ella verdad o falsedad. Es urgente la actitud crítica y el criterio para acoger o no una persona o una idea de internet. Puede sí ser a veces herramienta para encontrar una buena relación. Es interesante también tocar el tema del contenido sexual en la red. Es materia muy presente en ella y es una de sus características más polémicas. Es cierto que internet contiene material sexual que aparece en páginas emergentes no deseadas; es muy fácil encontrar páginas eróticas y que incluso pueden llegar al buzón personal en forma de spammers, como invitaciones para visitar sitios eróticos. Es verdad también que el anonimato del ciberespacio puede llevar a situaciones desagradables y que personas carentes de valores pueden exponer fotografías inadecuadas. Otro aspecto a considerar es que, muchas veces, se da una cosificación de la mujer que olvida los aspectos éticos y morales. Y, más grave aún, es el tema de la pornografía infantil y de la posibilidad de contacto de menores con pedófilos. Por todo lo anterior es necesario preguntarse chasta dónde este contenido sexual puede llevar a cambios negativos en la conducta de los jóvenes? Toca a los padres y educadores, básicamente, la responsabilidad de acompañar sugiriendo que ellos mismos limiten el ingreso a determinados sitios de la web. Lo adecuado sería que existieran sistemas de calificación de la propia web, por edades, que permitieran o no, incluir sitios sólo para adultos.

Respecto al uso del tiempo, es una realidad que internet puede ayudar a ahorrar tiempo comprando a través de la red o cancelando la cuota de la universidad desde el hogar; pero, por otro lado, este servicio es oportunidad para caer en el síndrome de adicción a internet. La pregunta fundamental es si internet puede provocar este síndrome; lo cierto y posible de constatar es que muchas personas "no tienen tiempo para nada" porque están pegadas a internet utilizándolo de manera excesiva y dejando de lado otras responsabilidades. Internet tiene espacios y posibilidades muy atractivas. Los jóvenes dejan de lado los estudios por jugar o bajar música, entre otras atracciones tan absorbentes que algunas personas pueden acabar abusando de ellas compulsivamente. Dice, Wallace (2001): "Como de costumbre todo lo que tiene que ver con internet, $y$ con nuestra relación con ella, acaba adquiriendo unas proporciones desmesuradas, por lo que la cuestión de la "adicción" a internet ha sido objeto de intensos debates $y$ de grandes exageraciones. Con todo, detrás de los relatos sensacionalistas se encuentran personas con problemas porque dedican tanto tiempo a la red que parecen ser incapaces de apartarse de ella" (2001, p.228).

Tendríamos que preguntarnos por qué se da esa adicción; si son causa la facilidad y el bajo costo para el acceso a internet, la estimulación visual, el anonimato. Esta adicción a la red puede llevar a casos extremadamente graves como el que sucedió, en Korea, según lo publicado en el diario La República del 7 de marzo del 2010: "Una pareja surcoreana adicta a un ciberjuego en el que se trata de criar a un niño virtual, fue arrestada por descuidar a su hija real de tres meses y dejarla morir de hambre. La pareja halló muerta a su bebé al regresar a su casa, tras pasar toda la noche jugando en un internet café. El padre de 41 años y la madre de 25. desempleados los dos, se ocultaron en la casa de un pariente después de que la autopsia policial halló que el bebé murió por falta de alimentos". 
Corresponde de manera especial a padres y educadores preocuparse por la formación de los jóvenes; a través del diálogo, ayudándolos a reflexionar sobre la urgencia de mantener la privacidad, defendiendo los propios datos privados. Los padres tienen la responsabilidad también de acompañar las actividades de sus hijos en internet y en las redes que frecuenten.

El amor a la cultura propia y universal es un valor. Internet puede ayudar y ayuda porque hay portales como el Portal Artístico y Cultural Peruano, el Portal Cultural de la Región Andina y muchos más que los jóvenes necesitan conocer, visitar y valorar. La red social YouTube es espacio aprovechado para difundir la cultura; así la orquesta sinfónica de Nueva York, integrada por músicos de 33 países, se formó gracias a la selección de artistas hecha a través de YouTube. El peruano Marco Antonio Mazzini fue uno de los seleccionados, como se puede leer en la página www.youtube. com/sinfoniorchester. El concierto fue trasmitido en línea. Desde el 10 de marzo del 2010, contamos con el portal www.artesaniasdelperu.gob.pe con la finalidad de promover el desarrollo de los artesanos peruanos, dando a conocer sus productos. Es interesante que se cuente con un directorio de artesanos; sirve para dar a conocer ferias, exposiciones, concursos, foros y becas, entre otros.

Los jóvenes necesitan vivir en honestidad $y$ honradez. Es necesario conocer las nuevas modalidades de delincuencia informática porque, como sabemos, hay delincuentes informáticos que operan con nexos extranjeros. Cuentas bancarias son vaciadas impunemente. Uno de los fundamentos de la interactividad es la participación que también es un valor. Definitivamente la tecnología digital online trae en su propia esencia la dimensión comunicacional que permite al joven actuar como emisor, como colaborador y como co-creador. Hablando de valores en la red, no se puede olvidar el valor importante del servicio a los demás y este altruismo sí se da en la red. Según Wallace "se producen muchos gestos de bondad y generosidad y muchas personas se quedarian muy sorprendidas al ver lo altruistas que pueden ser los usuarios de la red" (2001, p.243). Un ejemplo: en enero del 2010 se produjo un fuerte sismo, de 9.9 grados en la escala de Richter en Haití. Internet, desde el primer momento, fue una valiosa herramienta de ayuda. Según Bruno Ortiz Bisso, (2010), la ayuda prestada por internet fue valiosa en varios niveles "cuando la red de comunicaciones colapsó, los sobrevivientes usaron redes sociales, como Twitter, para informar al mundo sobre la situación en Puerto Príncipe". Además, la red permite hacer donaciones directas a quienes lo necesitan. La solidaridad es un valor importante, sobre todo en países en vías de desarrollo. Así, el portal Nutrinet Peru, abierto el 2009, tiene como misión informar, educar y ayudar a la toma de conciencia sobre la importancia de lucha contra la desnutrición y el hambre en el Perú, en América Latina y el Caribe, mejorando así los conocimientos en nutrición y las condiciones de vida de los países más necesitados. En febrero del 2010, un sismo grado 8.8 en la escala de Richter azotó el país de Chile. Las redes sociales ofrecieron un buen servicio. Un peruano, Enrique Escardó, aprovechó Twitter solidarizándose con cuantos necesitaban su apoyo. Actualmente las nuevas tecnologías favorecen la difusión del Evangelio de Jesús, con su mensaje de solidaridad; la Buena Noticia llega a muchos a través de internet; hay sitios católicos como Eclesalia que dan noticias y mensajes del pensamiento de la Iglesia. Es una manera de aprovechar la tecnología para lo que podría considerarse pastoral virtual, entrando así en la era digital, para una nueva evangelización. 


\section{Situaciones negativas en las redes sociales.}

\subsection{La ciberadicción.}

Es un trastorno de adicción a Internet (IAD) sigla en inglés (Internet Addiction Disorder). Aunque no está oficialmente clasificado como trastorno real en el Manual Diagnóstico y Estadístico de Trastornos Mentales, muchas personas insisten en que es un trastorno real y que debería ser incluido, dado que es una realidad negativa que crece en todo el mundo. Se trata de personas - niños, adolescentes, jóvenes y adultos - que tienen un uso excesivo de las redes sociales. Por este motivo se pierde el sentido del tiempo y/o se descuidan necesidades básicas como ducharse, alimentarse o dormir. La persona adicta presenta síntomas de retraimiento: mal humor, tensión o depresión, cuando no es posible el ingreso a internet. La ciberadicción trae consigo repercusiones negativas en la conducta cotidiana: fatiga, discusiones en el hogar, problemas en el estudio, engaño, aislamiento, falta de progreso. Crea fuerte dependencia en el joven. La persona llega a arriesgar la pérdida de una relación significativa, un trabajo, una oportunidad profesional o educativa a causa del uso excesivo de Internet. Miente para ocultar el uso real que hace de él. Lo utiliza como forma de escape de problemas cotidianos o a veces como intento de mejora cuando siente ansiedad o depresión. Lleva al joven a disminuir el esfuerzo en los estudios, a ausentarse de la universidad y olvidar sus responsabilidades. Se hunde en lo que ve como refugio para conflictos familiares: busca la soledad y llega hasta la ruptura con la familia. Por estos motivos, es necesario que el joven supere el uso excesivo de juegos en línea, las visitas permanentes a redes sociales, el continuo y obsesivo uso de correo electrónico, las compras compulsivas, etc.

\subsection{El Ciberbullying o acoso cibernético.}

Esta palabra es derivada del inglés bully cuya traducción literal es "matón". Hay diferentes tipos de bullying: físico, virtual, verbal, psicológico y social. El bullying virtual se refiere a personas que asustan o amedrentan, agreden o intimidan a otras para conseguir sus objetivos, a través de las redes sociales.El avance de las nuevas tecnologías abre las puertas al ciberbullying. Actualmente hay páginas web que, gracias a su libre acceso y manejo fácil, son muy utilizadas; por ejemplo la página memegenerator.es crea "memes" sarcasmos que se difunden por internet - con la finalidad de burlarse expresando con frecuencia actitudes de intolerancia y discriminación. Hay diferentes formas de acoso a través de las redes: verbal o visual, con contenidos denigrantes y/o pornográficos, a través de frases o de imágenes, que suelen enviarse de manera anónima y permanentemente.

\subsection{El Happy-Slapping.}

El término "happy-slapping": divertirse abofeteando, se refiere a un hostigamiento virtual que se convierte en verdadero tormento para la víctima. Se consiguen contenidos en base a grabaciones clandestinas de pequeños abusos, por ejemplo situaciones de maltrato. Subidas a la red y difundidas, palabra o imagen, se envían en forma veloz como si fueran virus. Muestran diferentes ataques como un juego para divertirse y normalmente son de carácter grupal. El Happy-Slapping puede traer consecuencias negativas, tanto para la víctima como para el agresor, por ser un acto planificado. Este tipo de hostigamiento va acompañado de risas como si fuera una simple broma y no un hecho violento, lo que puede dificultar que sea considerado merecedor de sanción. Este tipo de acoso debería ser denunciado. 


\subsection{El peligroso Grooming.}

La palabra groom en inglés significa arreglar, acicalar. Se trata de engañar a través de conversaciones en la red, consiguiendo objetivos que hacen daño a las personas, bajo el nombre de una falsa amistad. A través de la manipulación de sentimientos, se consigue datos personales de la víctima e incluso fotos, con las que luego se hace chantaje, buscando la satisfacción sexual. Puede llevar a situaciones muy dolorosas para la víctima. Actualmente hay organizaciones con servicios especializados para identificar el grooming y advertir a las personas sobre este peligro. También hay restricciones para proteger especialmente a los niños de pedófilos que buscan tener conversaciones de carácter sexual y aprovechar de ellos, puesto que suelen tener como objetivo la pornografía infantil.

\subsection{El Morphing.}

Se trata de una técnica utilizada por personas que copian una fotografía normal de internet y realizan un montaje, utilizando dicha técnica para arreglar y convertir esa fotografía en otra pornográfica. El resultado es una nueva versión con contenidos eróticos, por ejemplo un niño como protagonista en una imagen de alto contenido sexual. La consecuencia puede ser una situación traumática para el niño víctima. Una manera de evitar este tipo de problemas es evitar subir a la red fotos de primer plano, dado que son más fáciles de identificar y manipular.

\subsection{Tratamiento de la ciberadicción.}

Siendo la ciberadicción un problema grave de salud, hay esfuerzos notables en búsqueda de soluciones. En China hay campamentos para curar la ciberadicción, dado que ya en el 2009 había 24 millones de ciberadictos. El 2010 habían 250 centros de rehabilitación, con un fuerte régimen para lograr hábitos de disciplina: los enfermos son invitados a limpiar, cocinar, trabajar sin ningún contacto con aparatos tecnológicos; en cambio se organizan para ellos ejercicios físicos, momentos musicales, actividades relajantes. Tienen sesiones periódicas con psicólogos. El presidente de la Asociación Italiana de Psicólogos y Psiquiatras, Dr. Tonino Cantelmi, ha desarrollado una terapia para tratar la ciberadicción. Este científico, psiquiatra de la Universidad Católica Gregoriana de Roma, trata frecuentemente a los llamados retemaníacos que presentan crisis de abstinencia, manifestadas con agitación psicomotriz y obsesiones con la red telemática. Hay pacientes graves que padecen el llamado IAD que, muchas veces con ayuda de psicólogos o psiquiatras, toman conciencia de la gravedad del mal que padecen y, para salvarse, guardan la computadora bajo llave o se suicidan en la red, es decir se desconectan. Actualmente existe una posibilidad virtual: Suicide Machine, que permite a los usuarios, que lo desean y buscan, suicidarse al estilo Web 2.0 borrando todos sus datos de las redes sociales, sin poder recuperarlos.

La adicción a la red debe ser tratada, en principio, como cualquier otra adicción, aunque tenga características diferentes. Los pasos a seguir pueden ser: a) reconocimiento de la situación, asumida por el propio enfermo adicto al ciberespacio, b) automotivación o motivación externa para dejar el vicio, c) inicio de tratamiento con psicólogo o psiquiatra hasta el momento de internamiento en un centro especializado. En el Perú existen ya Centros de Rehabilitación como son: Asociación Terapéutica Proyecto Vida, Asociación Terapéutica Profesional Vida, Caminando a la Vida, Centro de Rehabilitación Amor 
de Cristo, Casa Nueva Vida, Centro de Rehabilitación de Adicciones- Modelo Naña (estatal). Para ayudar a estos enfermos, se ha fundado una asociación de navegantes anónimos que, como en el caso de los alcohólicos anónimos, comprende y ayuda a superar este peligroso vicio.

\section{A modo de conclusión.}

Conviene preguntarse si la familia ayuda y orienta; si se prepara a la juventud para hacer frente a la enorme cantidad de información que constantemente recibe desde múltiples medios, de modo tal que pueda aprovecharla. Preguntarse si se educa en actitud crítica frente a la información y a los productos culturales que se difunden a través de las redes. El papel de la familia y de los educadores, en general, es fundamental para una adecuada orientación. Es responsabilidad del mundo adulto orientar sobre el uso adecuado de los entornos educativos; la utilización de las Web 2.0 y 3.0, específicamente de las redes sociales, siempre en vista del crecimiento de la persona. Conviene recomendar que los adultos $\mathrm{y}$, especialmente los padres $\mathrm{y}$ educadores, ayuden a la juventud para que tengan una mirada crítica sobre el uso de las redes y del material que puede llegar a través de internet. A los jóvenes les queda aprovecharlas, dialogar, mantener la actitud crítica, reflexionar sobre su importancia y posibilidades. A los padres les compete asesorarse y buscar formas de crear ambientes sanos de comunicación y confianza. La seguridad es un tema esencial ante este nuevo mundo virtual. La responsabilidad de los educadores es capacitarse ante estos desafíos, orientar a los estudiantes, indagar por el uso que se le da a la red y comprometerse también por crear ese ambiente sano y de confianza con el cual estar alerta ante las posibles situaciones venideras.

\section{REFERENCIAS}

Artesanías del Perú (2010). Marzo. Mes de la artesanía peruana 2010. Recuperado el 25 de marzo del 2010 de http://www. artesaniasdelperu.gob.pe/.

Cabero J \& Duarte, A.M. (2002). Nuevas Tecnologías Aplicadas a la Educación. Madrid: Ed. Libro Amigo.

Castaño, C. etal. (2008). Prácticas Educativas en Entornos Web 2.0. Ed. Síntesis S.A.

Congreso de la República (2007). Ley No 29139. Recuperado el 30 de abril del 2010 de http://www.munipicsi.gob.pe

Faerman, J. (2009). Faceboom. El nuevo fenómeno de masas facebook. Buenos Aires: Ediciones B Argentina S.A.

Mayans i Planells, J. (2002). Género Chat o cómo la etnografía puso un pie en el ciberespacio. Barcelona: Ed.Gedisa.

Perinat Maceres, A. (2003). Los adolescentes en el Siglo XXI. Barcelona: Ed. UOCSI

Prensky Marc (2010) Nativos e inmigrantes digitales. Distribuidora SEK, S.A.

Quiroz, M.T. (2004) Jóvenes e Internet. Entre el pensar y el sentir. Lima: Fondo de Desarrollo Editorial.

Vaticano (2009). Vaticano lanza un sitio de internet para jóvenes: Pope2you.net. Recuperado el 30 de mayo de 2009 de htpp://www.pope2you.net

Wallace, P. (2001) La Psicología de Internet. Barcelona: Paidós. 